\title{
An apparent duplication of the mouth in a patient with midline dysraphism and a teratoid polyp: A 15-year postsurgical follow-up
}

\author{
Craig Stewart MD MSc, Lowell A Hughes MBBSHons FRCSEd, Hugh G Thomson MD MS FRCSC, \\ Derek Armstrong MBBS FRCPC, Vito Forte MD FRCSC
}

C Stewart, LA Hughes, HG Thomson, D Armstrong, V Forte. An apparent duplication of the mouth in a patient with midline dysraphism and a teratoid polyp: A 15-year postsurgical followup. Can J Plast Surg 2007;15(4):227-229.

True median cleft of the upper and lower lip occurs very rarely. Complete or partial facial duplication is an extremely rare malformation. Approximately 26 cases have been reported since 1900, spanning a wide spectrum of clinical severity. Most cases appear to share a number of features, including cleft palate, duplication of the tongue, orbital hypertelorism and macrostomia. An unusual patient with midline clefts of the upper and lower lips with an apparent duplication of the mouth and a teratoid polyp, with fusion of the maxilla and mandible, is reported. The early management and surgical intervention is discussed. Furthermore, postoperative outcomes are reviewed as part of a 15-year postsurgical follow-up.

Key Words: Dysraphism; Mouth duplication; Teratoid polyp

\section{CASE PRESENTATION}

The patient was the first-born female to healthy parents, delivered at 39 weeks gestation via spontaneous vaginal delivery with outlet forceps. At birth, she was noted to have an apparent duplication of the mouth with clinical fusion of the jaws. There was a midline pit at the base of the columella with a median cleft of the upper lip. There was also a cleft of the lower lip and chin with a small 'blob-like' piece of tissue between the hemichins, giving a three-chin point appearance (Figure 1).

The cleft margins of the upper and lower lips were fused to the gingiva and central chin 'blob', producing an apparent 'double mouth' (Figure 2).

Other notable clinical features included a broad nasal root and orbital hypertelorism. Clinically, the median cleft did not extend through the frontal cranial bones as in the Tessier 0 to 14 classification.

Both nasal passages were patent, but mouth opening was impossible; thus, oral feeding and intraoral examinations were clinically impossible.

\section{Appraisal}

Hematological and biochemical investigations revealed normal values, and hormonal studies were also within normal limits, ruling out the possibility of pituitary deficiencies, which
Duplication apparente de la bouche chez une patiente présentant une dysraphie médiane et un polype tératoïde : Suivi post-chirurgical après 15 ans

Les fissures médianes vraies de la lèvre supérieure et inférieure sont très rares. Une duplication faciale complète ou partielle est une malformation d'une rareté extrême. Environ 26 cas ont été rapportés depuis 1900 et se sont manifestés selon divers degrés de sévérité. La plupart des cas avaient en commun plusieurs caractéristiques, y compris la fissure palatine et la duplication de la langue, l'hypertélorisme orbital et la macrostomie. Les auteurs présentent ici un rare cas de fissure médiane des lèvres supérieure et inférieure avec duplication apparente de la bouche et polype tératoïde, accompagné de fusion du maxillaire et du mandibule. On aborde la prise en charge initiale et l'intervention chirurgicale. De plus, l'issue postopératoire est passée en revue dans le cadre d'un suivi post-chirurgical après 15 ans.

have been reported in cases with varying severity of holoprosencephaly.

Computed cranial tomography revealed an abnormal-looking bony mass situated between the vomer superiorly and the left parasymphyseal region of the mandible inferiorly (not shown). The mass extended as far posteriorly as the pterygoid plates, and there were numerous teeth within this tumour, suggestive of a teratoma. A complete midline cleft of the primary and secondary palates was also noted on this study.

Magnetic resonance imaging confirmed the agenesis of the corpus callosum suggested by the computed tomography scan, and also indicated normal positioning of the carotid and vertebral vessels. The tongue was displaced to the right side and somewhat posteriorly in the oral cavity.

\begin{abstract}
Management
Airway management and feeding were immediate concerns at presentation to the neonatal unit at the Hospital for Sick Children. A tracheotomy was performed under ketamine and local anesthesia on day 6 to protect the airway. Subsequently, nasogastric tube feeding could be commenced without the concern for regurgitation or emesis causing asphyxiation. Definitive operative plans and models were formulated by interdisciplinary discussions among plastic surgery, otolaryngology
\end{abstract}




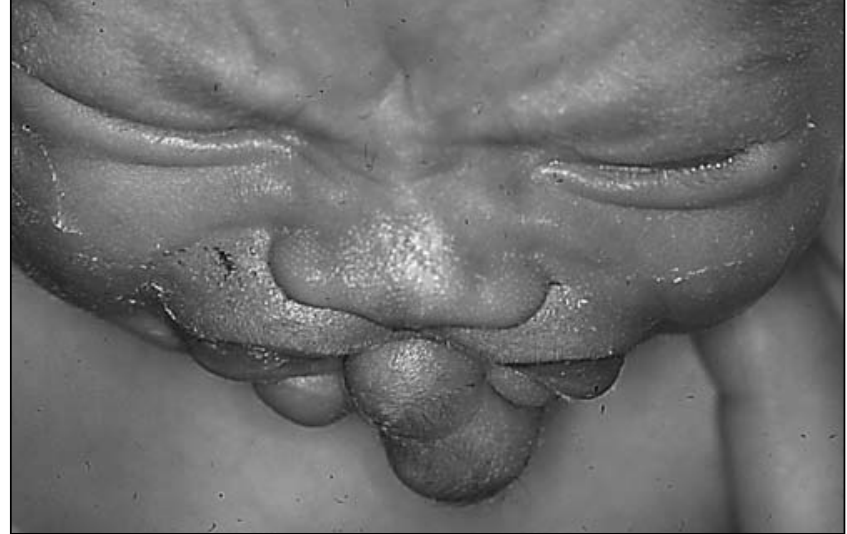

Figure 1) Apparent duplication of the mouth with clinical fusion of the jaws. A midline pit with a median cleft of the upper lip is seen. The cleft of the lower lip and chin is associated with a small 'blob-like' piece of tissue between the hemichins, giving a three-chin point appearance

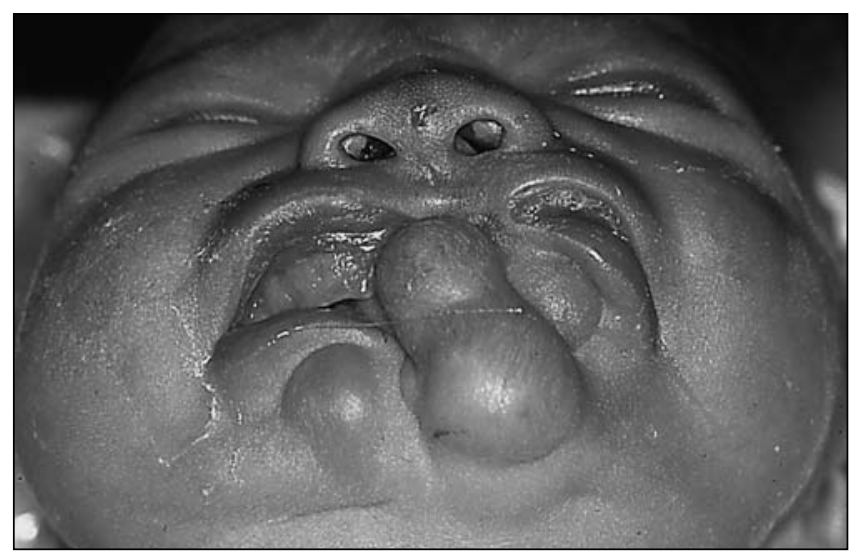

Figure 2) 'Double-mouth' created by fusion of the cleft margins of the upper and lower lips to the gingiva

and neuroradiology, while the child was permitted to gain weight before surgical intervention.

\section{Operative treatment}

At six weeks of age, the patient was taken to surgery where she had removal of the abnormal bony mass from the oral cavity via a direct approach.

The mucosa over the lesion was excised in the region of the gingiva anteriorly and separated from the bony mass, creating two flaps of mucoperiosteum. The flap on the left was based superiorly and that on the right inferiorly.

The lesion was osteotomized at the parasymphyseal region of the left hemimandible and removed in fragments with the use of rongeurs (Figure 3). Separation from the other attachments with the vomer and pterygoid plates was relatively easy and uneventful.

This mass gave the impression of a partially reduplicated premaxilla and vomer.

The mucoperiosteal flaps were subsequently used to resurface the floor of the mouth, including the exposed lingual mandibular surface, and to repair one side of the cleft palate (Figure 4).

The median cleft lip was repaired with a z-plasty technique. The lower lip was reconstructed in a similar fashion internally

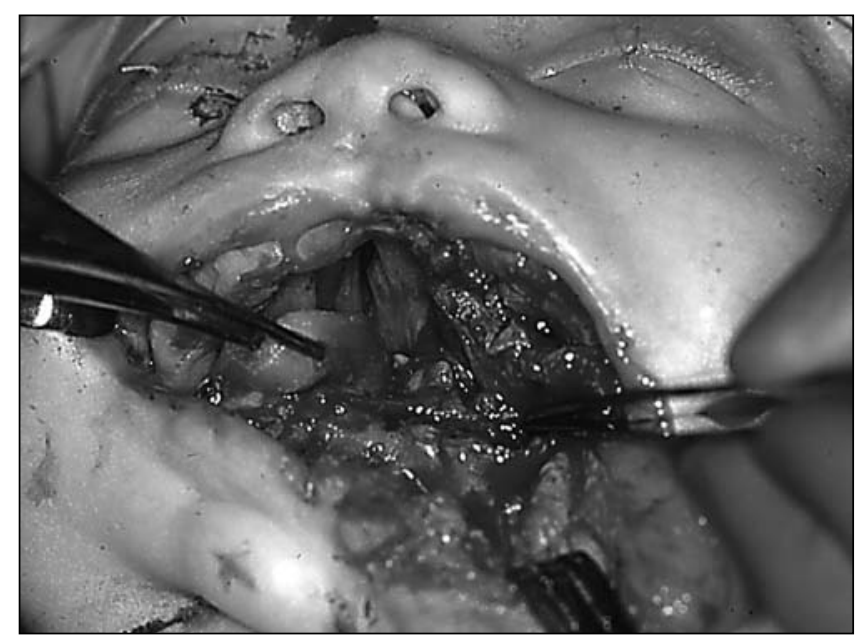

Figure 3) Resection of the lesion at the parasymphyseal region of the left hemimandible via osteotomies

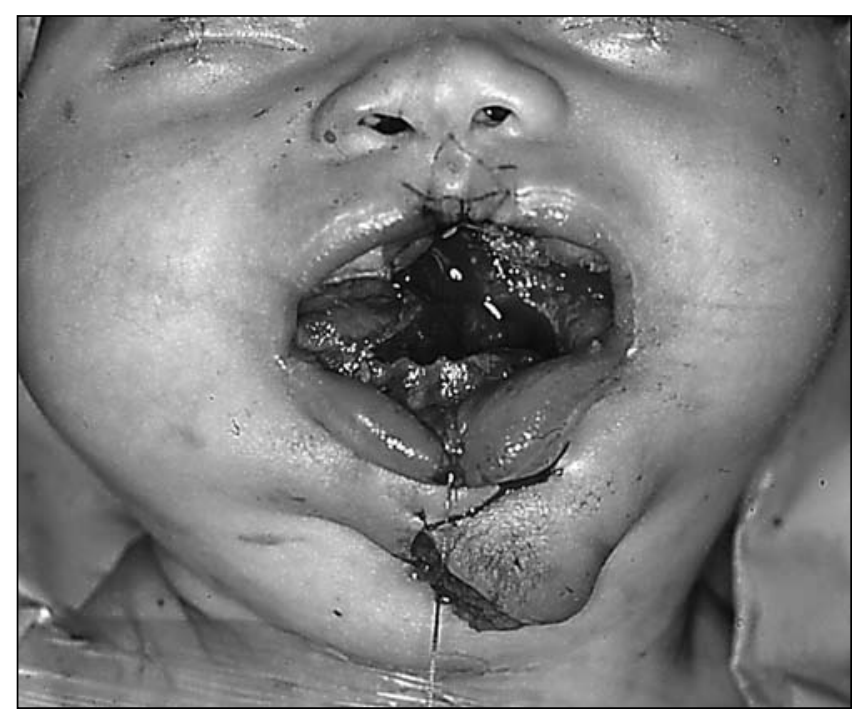

Figure 4) Mucoperiosteal flaps were employed for reconstruction of the floor of mouth postresection. Unilateral cleft palate repair and mandibular coverage were achieved

and quadrilateral flaps were employed on the mucosal and vermilion surfaces. The central 'blob' of tissue was rotated and transposed to augment the deficient micrognathic chin (Figure 5).

\section{Postoperative course}

There was significant cosmetic and functional improvement with the ability to now open the jaws. At two weeks postoperatively, the patient was started on oral fluids under the supervision of the occupational therapy feeding specialist. The patient tolerated small amounts of oral fluids and gradually developed a strong sucking ability.

At 12 weeks of age, a percutaneous gastric tube was inserted because progress with oral feeding was slow and inadequate to sustain nutritional needs without nasogastric tube feed supplementation. This tube was maintained until palatal surgery was completed, with continuation of oral training during that time.

The surgical pathology report was "a teratoid polyp with skin appendages, fibrous connective tissue, skeletal muscle, bone and numerous teeth. No evidence of malignancy noted". 


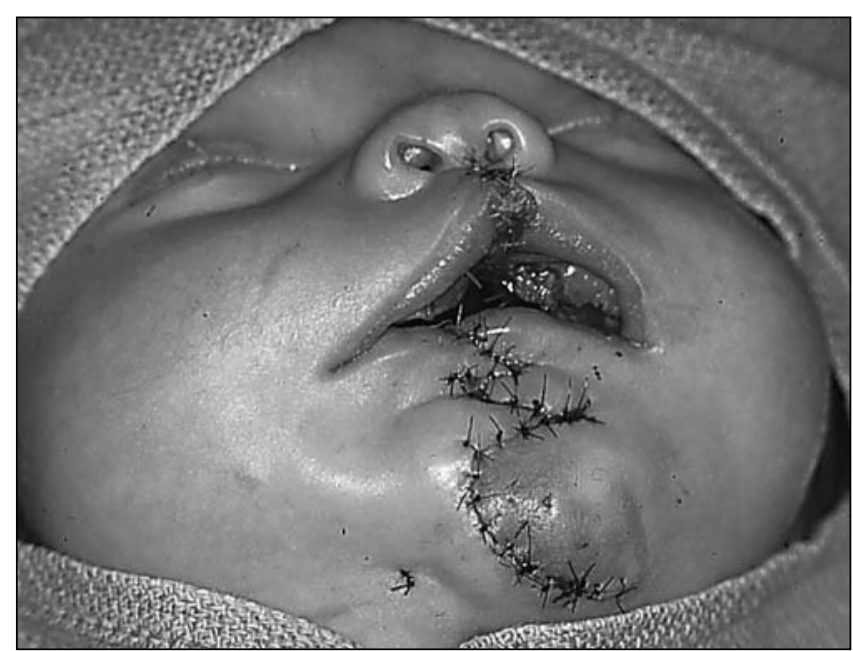

Figure 5) Median cleft lip repair using z-plasty. The central 'blob' of tissue was mobilized and rotated to augment the chin as shown

The patient was enrolled in the Cleft Palate Program and has enjoyed a successful postoperative course. She was decannulated and maintains good oral-motor competence with respect to mastication and speech (Figure 6). She is pleased with her surgical outcome and cosmetic result.

\section{DISCUSSION}

Complete or partial facial duplication is an extremely rare malformation. Approximately 26 cases have been reported since 1900, spanning a wide spectrum of clinical severity. Most cases appear to share a number of features, including cleft palate, duplication of the tongue, orbital hypertelorism and macrostomia (1-6)

Facial duplication may occur symmetrically or unilaterally, and it ranges from localized anomalies to complete doubling of all facial elements (diprosopus) (7).

The variety of patterns of duplication suggests that the doubling of facial components arises in several different ways. These include forking of the notochord, duplication of the prosencephalon, duplication of the olfactory placodes, and duplication of maxillary and/or mandibular growth centres around the margins of the stomodeal plate (2). Based on the structural abnormalities and presumed embryological mechanisms, facial duplication appears to represent both a clinically and pathogenetically heterogeneous malformation sequence in which overlapping findings are present (6).

This malformation sequence is apparently the combined result of a primary developmental duplication and a cascading secondary mass effect from the duplicated structures interrupting further normal development (7).

In our patient, median clefts of the lips, with partial duplication of the premaxilla and an intraoral teratoid polyp resulting in apparent duplication of the mouth, as well as fusion of the jaws, represented the major structural defects. Additional clinical features observed in our patient and in the majority of similarly affected patients included orbital hypertelorism, agenesis of the corpus callosum, cleft palate, broad nasal dorsum, supernumerary maxillary teeth and anomalies of the cervical vertebrae (6).

In spite of all that has been written about the embryology of the face, a full explanation of most of these rare clefts and facial anomalies still defies our present knowledge (8).

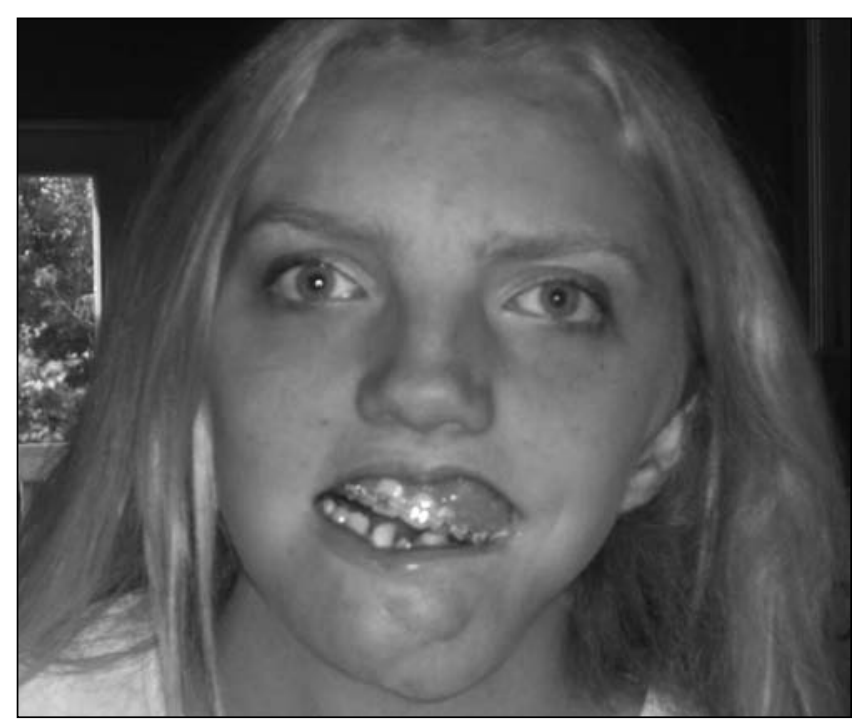

Figure 6) Fifteen-year postsurgical outcome. Patient enjoys oralmotor competence with satisfactory cosmetic results

Most pediatric plastic surgeons have not seen many or any of these unusual congenital anomalies and thus, there are no guidelines in the literature as how to manage these special patients.

We would like to highlight the importance of reverting to first principles, and the multidisciplinary approach to evaluation, assessment, operative planning, surgical treatment and rehabilitation.

Close collaboration among the pediatrician, otolaryngologist, plastic surgeon, neuroradiologist and geneticist greatly enhanced the full assessment and management of the present patient. The surgery was performed by the plastic surgeon and otolaryngologist assisting each other simultaneously.

\section{SUMMARY}

A very rare patient with median clefts of the upper and lower lips, with teratoid polyp producing fusion of the jaws and apparent duplication of the premaxilla and mouth is reported.

Our experience with the early management of this unusual case has been discussed, highlighting the importance of a multidisciplinary approach to evaluation assessment and management.

\section{REFERENCES}

1. Akpuaka FC, Nwozo JC. Reduplication of the mouth and mandible. Plast Reconstr Surg 1990;86:971-2.

2. Barr M Jr. Facial duplication: Case, review, and embryogenesis. Teratology 1982;25:153-9.

3. Bell RC. A child with two tongues (oral-facial-digital syndrome). Br J Plast Surg 1971;24:193-6.

4. Nakamura J, Tomonari H, Goto S. True median cleft of the upper lip associated with three pedunculated club-shaped skin masses. Plast Reconstr Surg 1985;75:727-31.

5. Price JE Jr, Zarem HA. Duplication of the mandible. Plast Reconstr Surg 1978;64:104-5.

6. Verdi GD, Hersh JH, Russell LJ. Partial duplication of the face: Case report and review. Plast Reconstr Surg 1991;87:759-62.

7. Fearon JA, Mulliken JB. Midfacial duplication: A rare malformation sequence. Plast Reconst Surg 1987;79:260-4.

8. Chandra R. Congenital duplication of lip, maxilla, and palate. $\mathrm{Br} \mathrm{J}$ Plast Surg 1978;31:46-7. 